\title{
Autoconceito e Autoeficácia em Crianças com Deficiência Física: REVISÃo Sistemática da Literatura ${ }^{1}$ \\ SELf-Concept and Self-EFficaCy in Children With Physical Disabilities: SySTEMATIC REVIEW OF LITERATURE
}

\author{
Alyne Kalyane Câmara de OLIVEIRA² \\ Thelma Simóes MATSUKURA ${ }^{3}$ \\ Anne Marie Germaine Victorine FONTAINE ${ }^{4}$
}

\begin{abstract}
RESUMO: a presente pesquisa objetivou identificar estudos que investigaram sobre o autoconceito e a autoeficácia em crianças com deficiência física, evidenciar e discutir sobre o que eles têm revelado acerca das autoavaliaçóes nesta população. Trata-se de um levantamento bibliográfico com critérios de revisão sistemática da literatura. A busca foi realizada nas bases de dados eletrônicas MEDLINE, LILACS, SCIELO, Biblioteca Cochrane, Index Psi Periódicos, PubMed, PePSIC e Redalyc, utilizando os termos criança, autoeficácia, autoconceito, autopercepção, pessoas com deficiência e paralisia cerebral, além de seus respectivos em inglês. Após triagem e seleção dos artigos por meio de critérios de inclusão, sete estudos foram analisados. Observou-se que todos os estudos analisados são estrangeiros, apenas um deles aborda a autoeficácia e seis investigaram sobre o autoconceito especificamente em crianças com paralisia cerebral. Os resultados sugerem que não há conformidade sobre o autoconceito em crianças com paralisia cerebral, sem evidências suficientes para concluir que este constructo seja inferior nestas crianças. Em relaçâo a autoeficácia, crianças com deficiência física se classificam como menos competentes que crianças com outros problemas no neurodesenvolvimento. Considera-se que novas investigaçôes são necessárias para confirmar o que a literatura sugere sobre o autoconceito e a autoeficácia em crianças com deficiência física, incluindo investigação no cenário brasileiro e contribuindo para o conhecimento de profissionais da Educação e Saúde acerca das autoavaliaçôes nesta população.
\end{abstract}

PALAVRAS-CHAVE: Educação Especial. Criança. Autoconceito. Autopercepção. Paralisia cerebral.

\begin{abstract}
The present review aimed to identify studies, which investigated self-concept and self-efficacy in children with physical disabilities, highlights and discusses what they have revealed about the self-assessments in this population. It is a literature review with systematic review criteria. The search was conducted in MEDLINE, LILACS, SCIELO, Cochrane Library, Index Psi Journals, PubMed, PePSIC and Redalyc databases using the terms child, self-efficacy, self-concept, self-perception, disabled persons and cerebral palsy, as well as their respective in Brazilian Portuguese. After screening and selection of articles using the inclusion criteria, seven studies were analyzed. It was observed that all of the analyzed studies are foreign, just one of them deals with self-efficacy and six investigated self-concept specifically in children with cerebral palsy. Results suggest that there is no compliance on self-concept of children with cerebral palsy, and there is no sufficient evidence to conclude that this construct is lower in these children. Regarding self-efficacy, children with disabilities are classified as less competent than children with other problems in neurodevelopment. It is considered that further investigations are needed to confirm the literature suggestions about self-concept and self-efficacy in children with physical disabilities, including this research in the Brazilian scenario, contributing to education and health professionals' knowledge about self-assessments in this population.
\end{abstract}

KEYWORDS: Special Education. Child. Self-Concept. Self-Perception. Cerebral Palsy.

\footnotetext{
${ }^{1}$ http://dx.doi.org/10.1590/S1413-65382317000100011

${ }^{2}$ Doutoranda em Educação Especial pela Universidade Federal de São Carlos. Professora Assistente do Departamento de Terapia Ocupacional da Universidade Federal da Paraíba. São Carlos, SP, Brasil. alynekoliveira@hotmail.com

${ }^{3}$ Professora Associada do Departamento de Terapia Ocupacional da Universidade Federal de São Carlos. Docente do Programa de Pós-Graduação em Terapia Ocupacional e do Programa de Pós-Graduação em Educação Especial da Universidade Federal de São Carlos. São Carlos, SP, Brasil. thelma@ufscar.br

${ }^{4}$ Professora Catedrática do Departamento de Psicologia da Faculdade de Psicologia e de Ciências da Educação da Universidade do Porto. Porto, Portugal. fontaine@fpce.up.pt
} 


\section{INTRODUÇÃo}

Em crianças com deficiência física, além dos comprometimentos motores da própria condição de saúde e dos fatores contextuais, acredita-se que a forma como a criança se autoavalia, como o autoconceito e a autoeficácia, podem levar a repercussóes na aprendizagem, no comportamento e na funcionalidade infantil (OLIVEIRA, 2016; PAJARES; VALIANTE, 1997; BANDURA et al., 1996).

Tendo como enfoque a funcionalidade infantil, ou seja, as habilidades que as crianças apresentam ao realizar tarefas do cotidiano, compreende-se que a limitação ou ampliação do repertório funcional possa ser influenciada pelo que a criança percebe de si mesma em diferentes domínios e de suas habilidades para desempenhar as atividades diárias, uma vez que cada pessoa possui um sistema de crenças que afeta seus pensamentos, sentimentos e consequentemente, suas açóes. Considera-se que as crianças são capazes de se engajarem em autoavaliaçóes, alterarem seu próprio pensamento e comportamentos subsequentes. Entre estas avaliações se inclui o autoconceito e a autoeficácia (SCHUNK, 1995; BANDURA, 1989).

$\mathrm{O}$ autoconceito ou autopercepção pode ser definido como conjunto de atribuiçóes cognitivas que uma pessoa faz a respeito de si, de suas características pessoais e de seu comportamento em situaçóes objetivas (CANDIEUX, 1996). Trata-se de um constructo multidimensional, no sentido de que envolve atribuiçôes em diferentes domínios, como conduta comportamental, aparência física, desempenho cognitivo/acadêmico, desempenho motor/atlético e aceitação social (HARTER, 1996; HARTER, 1985).

Explorado por diversas áreas, como a Psicologia, a Sociologia e a Educação, há consenso na literatura de que o autoconceito começa a ser construído na infância, a partir das interaçóes com os outros e das interpretaçóes que a criança faz do seu ambiente (FIERRO, 1996), podendo ser alterado ao longo da vida de acordo com as experiências que são significativas para cada pessoa (HARTER, 1996).

Pesquisadores buscaram ampliar os conhecimentos relacionados ao desenvolvimento do autoconceito, a partir da ideia descrita por Coopersmith $(1967)^{5}$ apud Faria e Fontaine (1995), de que as crianças recebem informaçóes sobre si mesmas dos adultos significativos em sua vida, e que, com base nessas impressóes recebidas, desenvolvem uma imagem positiva ou negativa sobre si mesmas.

Atualmente, sabe-se que o autoconceito é formado por (a) componentes afetivos, que seriam mais subjetivos e internos; (b) componentes sociais, mais relacionados com o significado que a conduta dos indivíduos tem para os demais; (c) componentes físicos, fundamentais nas atitudes e na aparência geral dos indivíduos e, (d) componentes acadêmicos, que dizem respeito ao sentimento que a criança tem perante seu contexto escolar e que, na maioria das vezes, é formado pela interação com os colegas e professores (SUEHIRO et al., 2009).

Enquanto o autoconceito possui caráter mais amplo, uma avaliação mais pura das capacidades e competências pessoais, com perspectiva multidimensional, a autoeficácia se refere ao autojulgamento diante de uma tarefa e contexto específico, relacionada às expectativas ligadas ao self e à percepção de sua própria capacidade, ou seja, uma avaliação daquilo que o

${ }^{5}$ COOPERSMITH, S. The antecedents of self-esteem. San Francisco: W. H. Freeman, 1967. 
indivíduo acredita ser capaz de fazer a partir das competências que possui (NEVES; FARIA, 2009; BANDURA; AZZI; POLYDORO, 2008).

O constructo autoeficácia ou competência percebida reflete a habilidade para avaliar sua própria capacidade em realizar uma determinada tarefa (MISSIUNA et al., 2006). De acordo com Bandura et al. (1996), o conceito de autoeficácia, originado da Teoria Social Cognitiva, envolve o julgamento da pessoa sobre sua capacidade para mobilizar recursos e agir para controlar demandas do ambiente.

O senso de autoeficácia também começa a ser construído na infância, quando a criança se percebe produzindo efeitos por meio das suas açóes, por exemplo, ao balançar um chocalho criando sons ou ao chorar para receber assistência dos pais, sendo as primeiras experiências centradas na família (BANDURA et al., 1996). Este autor relata que o desenvolvimento da autoeficácia se dá por intermédio das competências exigidas ao longo da vida de forma intuitiva: indivíduos se envolvem em atividades, interpretam os resultados de suas açóes, usam a interpretação para desenvolver crenças sobre sua capacidade e, ao envolverem-se em futuras atividades em domínios similares, agem de acordo com as crenças prévias.

Para Bandura et al. (1996) os julgamentos de autoeficácia atuam como mediadores entre os fatores que influenciam o comportamento, tais como aptidóes, conhecimentos, realizaçóes prévias e habilidades e o comportamento subsequente. Isto ocorre tanto por uma ação direta, como através do seu impacto no próprio autoconceito, nos processos de motivação, nas expectativas de resultados, bem como nas escolhas e interesses, que irão afetar o nível e o tipo de comportamento infantil (PAJARES; VALIANTE, 1997).

Este tipo de julgamento sobre si mesmo é um fator que permite à criança se perceber com a competência necessária para obter o seu próprio bem-estar, como um fator moderador da capacidade funcional na participação e qualidade de vida (BAUM; CHRISTIANSEN, 2005; BAYDALA; HIEBERT; MALEC, 2000).

A criança que possui uma percepção de autoeficácia positiva, mantém a crença de que é capaz de alcançar os resultados almejados para si, podendo fazer planos e traçar metas. Por outro lado, uma percepção de autoeficácia negativa pode levar ao abandono de uma estratégia ou comportamento durante determinada intervenção, estando a autoeficácia também relacionada à adesão terapêutica de crianças que necessitam de intervençóes especializadas na prática clínica (BANDURA, 1997; LENT; MADDUX, 1997).

De acordo com Fernandes e Milani (2010), as crenças de autoeficácia influenciam a vida da criança de uma forma generalizada. Para compreender a abrangência desta influência se faz necessário entender que, de maneira geral, tais crenças influenciam o envolvimento com metas estabelecidas, o nível de motivação, a perseverança frente às dificuldades e a resiliência às adversidades (MEDEIROS et al., 2000). Taylor et al. (2014) complementam que o autoconceito também é decisivo para a saúde e para o bem-estar ao longo da vida.

Assim como as autoavaliaçóes influenciam a motivação e a aprendizagem para a demanda de atividades, Bandura et al. (1996) apontam que fatores ambientais e pessoais também afetam estes constructos, na sua origem e desenvolvimento. 
Araújo (2012) descreve que a formação do autoconceito depende das consideraçôes e percepçóes que o indivíduo tem de si mesmo e, também do julgamento que os outros fazem dele, sobretudo, influenciado pelas interaçóes estabelecidas nos contextos familiar, social e escolar.

De acordo com Taylor et al. (2014), os principais fatores que influenciam o autoconceito incluem aspectos culturais, recursos internos e externos, experiências de sucesso e fracasso, eventos estressores e doença ou trauma. Dentre os fatores que afetam a autoeficácia estão as experiências, realizaçóes e desempenhos anteriores; experiência vicariante; persuasão social; estados fisiológicos e afetivos (BANDURA, 1997; BANDURA, 1986).

Somam-se aos apontamentos da literatura, consideraçóes acerca da importância que o desenvolvimento das autoavaliaçôes parece assumir na vida da criança com deficiência física (CORREDEIRA et al., 2007; DUNN; DUNN, 2006). Ao utilizar suas habilidades existentes nas atividades diárias e como elemento de valor motivacional para a aquisição de novas habilidades, que poderão ser incorporadas ao repertório funcional infantil, compreende-se como relevante identificar o modo como estas crianças se percebem em diferentes domínios, sendo que estas informaçóes podem ser úteis para os interessados em investigar e/ou intervir junto a esta população, seja em contextos educativos, terapêuticos ou sociais.

Nesta direção, como exemplo, Corredeira et al. (2007) apontam que o senso de autoeficácia motora é uma crença de grande interesse, pois se a criança com deficiência física tiver percepção acurada de suas habilidades, isso pode gerar motivação e facilitar o processo de intervenção com a mesma. Dunn e Dunn (2006) também destacam que existe uma lacuna para pesquisas nessa área, sendo importante aumentar o conhecimento sobre as relaçóes entre o senso de autoeficácia e o comportamento de crianças com dificuldades motoras em atividades físicas.

Desta forma, o presente estudo teve como objetivo identificar pesquisas que investigaram sobre o autoconceito e a autoeficácia em crianças com deficiência física, evidenciar e discutir sobre o que elas têm revelado acerca das autoavaliaçóes na população em questáo.

\section{Método}

O presente estudo trata-se de uma revisão sistemática da literatura, a qual consiste em "um sumário de evidências provenientes de estudos primários conduzidos para responder uma questão específica de pesquisa” (BRASIL, 2014).

Esta revisão seguiu etapas fundamentais (BRASIL, 2014), as quais nortearam os procedimentos de coleta e análise dos dados.

a) Definição da questão de pesquisa: foi a dotada a seguinte questão que guiou a revisão sistemática: o que os estudos que investigaram sobre o autoconceito e a autoeficácia em crianças com deficiência física têm revelado acerca das autoavaliaçóes nessa população?

b) Definiçâo dos critérios de elegibilidade: foram definidos os critérios de elegibilidade, de maneira que para serem considerados na revisão, os estudos deveriam responder aos seguintes critérios de inclusão: publicação no formato de artigo original; em idioma português, inglês ou espanhol; que abordassem os constructos autoconceito ou autoeficácia em crianças com deficiência física. 
c) Definição das bases de dados a serem pesquisadas: a pesquisa foi realizada no Portal de Pesquisas da Biblioteca Virtual em Saúde (BVS), que inclui várias bases de dados eletrônicas, como a Literatura Internacional em Ciências da Saúde (MEDLINE), Literatura da América Latina e do Caribe em Ciências da Saúde (LILACS), Scientific Eletronic Library Online (SCIELO) e Biblioteca Cochrane. As bases de dados Index Psi Periódicos, o PubMed, o Portal de Periódicos Eletrônicos de Psicologia (PePSIC), a Rede de Revistas Científicas de América Latina, Caribe, Espanha e Portugal (Redalyc) também foram utilizadas para busca.

d) Definição das estratégias de busca: considerou-se o período de publicação dos artigos entre os anos de 1995 e 2014, no período compreendido entre os dias quatro e 24 de maio de 2015, por meio de combinação entre os termos: criança, autoeficácia, autoconceito, autopercepção, pessoas com deficiência e paralisia cerebral, além de seus respectivos termos em inglês.

e) Processo de triagem e seleção dos artigos: por meio das etapas anteriores foram identificados artigos potencialmente elegíveis, totalizando 329 estudos que foram selecionados preliminarmente através da análise dos títulos e resumos.-Após a análise inicial 97 artigos foram considerados elegíveis. Destes, havia artigos repetidos em mais de uma base de dados, artigos que não permitiam ter acesso completo gratuito à obra, que tratavam do assunto direcionado a outra população, que focalizavam a análise de instrumentos/protocolos de autoavaliação, ou ainda, de outros constructos, como a autoestima. Muitas destas informaçóes só foram possíveis de identificar após a leitura na íntegra dos artigos, uma vez que havia resumos insuficientes, totalizando uma amostra final de 7 estudos. A Figura 1 apresenta síntese do processo de triagem e seleção dos artigos.

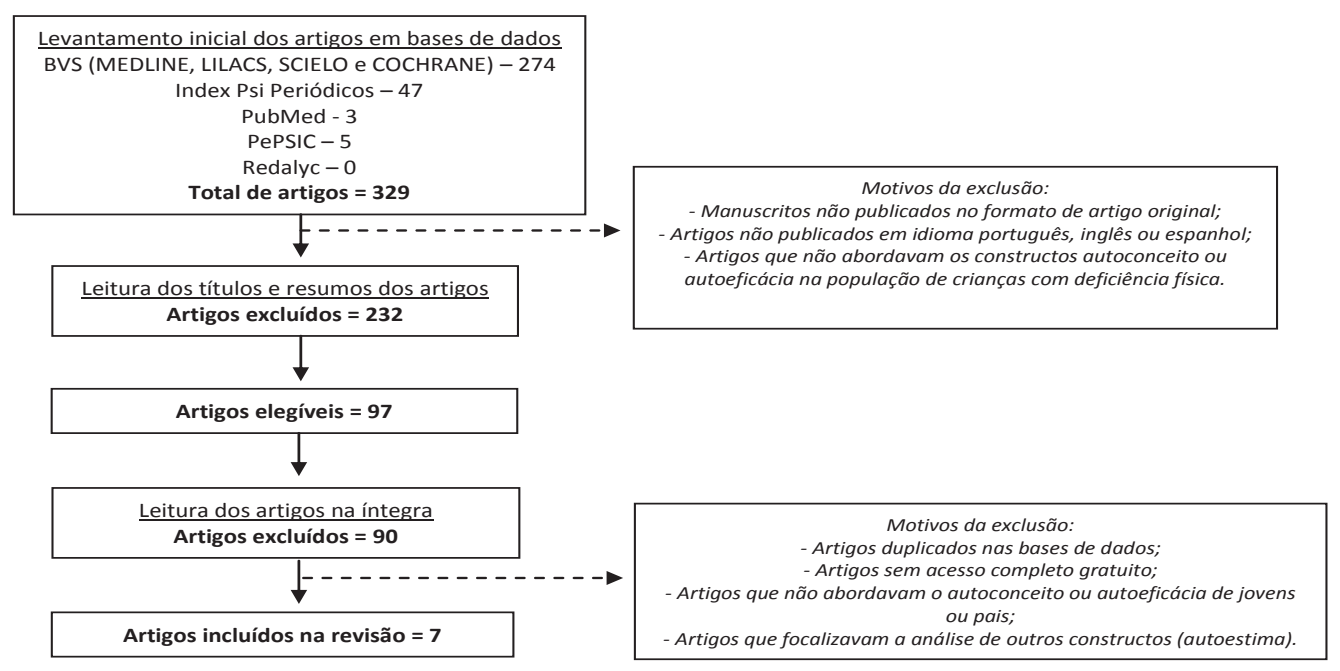

Figura 1- Fluxograma de triagem e seleção da amostra de artigos da revisão sistemática. Fonte: Elaboração própria. 


\section{APRESENTAÇÃo E ANÁLISE dOS DADOS}

Após o processo de triagem e seleção da amostra, os sete estudos incluídos na revisão são apresentados e discutidos a seguir. Os dados obtidos foram analisados descritivamente segundo o propósito da revisão em questâo, a partir de informaçóes que caracterizam os estudos e apontam os desfechos relacionados ao autoconceito e a autoeficácia em crianças com deficiência física. O Quadro 1 dispôe de uma síntese das principais informaçôes dos artigos.

\begin{tabular}{|c|c|c|c|c|}
\hline $\begin{array}{l}\text { Autoria, } \\
\text { ano e local }\end{array}$ & Objetivo do estudo & Desenho do estudo e amostra & $\begin{array}{l}\text { Variável investigada } \\
\text { e instrumento de } \\
\text { medida }\end{array}$ & $\begin{array}{l}\text { Desfecho em relação ao } \mathrm{AC} \\
\text { ou } \mathrm{AE}\end{array}$ \\
\hline $\begin{array}{l}\text { Soyupek et } \\
\text { al. (2010), } \\
\text { Turquia. }\end{array}$ & $\begin{array}{l}\text { Identificar se a QV e o } \\
\text { AC em crianças com PC } \\
\text { diferem dos de crianças com } \\
\text { DT; e investigar variáveis } \\
\text { preditivas que podem afetar } \\
\text { a QV e o AC das crianças. }\end{array}$ & $\begin{array}{l}\text { Transversal. } \\
86 \text { crianças, sendo: } 40 \text { com PC de } \\
\text { todos os níveis de gravidade motora } \\
\text { do GMFCS, com idade entre } 9 \text { e } \\
18 \text { anos, e } 46 \text { sem deficiência, de } \\
\text { mesma idade e gênero de seus pares. }\end{array}$ & $\begin{array}{l}\text { Autoconceito. } \\
\text { Piers-Harris } \\
\text { Self-concept Scale } \\
\text { de Piers e Harris } \\
(1969) \text {. }\end{array}$ & $\begin{array}{l}\text { Crianças com PC apresentaram } \\
\text { AC mais negativo em compa- } \\
\text { raçáo com as crianças sem PC. } \\
\text { Menores escores do AC foram } \\
\text { encontrados para crianças que } \\
\text { frequentavam escola especial } \\
\text { quando comparadas às que } \\
\text { estudavam em escola regular. }\end{array}$ \\
\hline $\begin{array}{l}\text { Dunn et al. } \\
\text { (2009), } \\
\text { Austrália. }\end{array}$ & $\begin{array}{l}\text { Investigar se há diferenças } \\
\text { entre o AC de crianças com } \\
\text { PC e a percepção de seus } \\
\text { pais em relação as habilida- } \\
\text { des das crianças; e avaliar a } \\
\text { força de associaçãa entre as } \\
\text { avaliaçóes das crianças e de } \\
\text { seus pais. }\end{array}$ & $\begin{array}{l}\text { Transversal. } \\
30 \text { crianças, sendo: } 14 \text { meninas } \\
\text { e } 16 \text { meninos, entre } 8 \text { e } 16 \text { anos } \\
\text { de idade, com hemiplegia ou } \\
\text { diplegia espástica, níveis I ou II do } \\
\text { GMFCS, e } 30 \text { pais. }\end{array}$ & $\begin{array}{l}\text { Autoconceito. } \\
\text { SPPC; Parent Rating } \\
\text { Scale de Harter } \\
(1985) \text {. }\end{array}$ & $\begin{array}{l}\text { Observaram diferenças entre } \\
\text { pais e crianças nos domínios } \\
\text { de competência atlética e } \\
\text { aparência física. Não houve } \\
\text { associaçáo entre os escores do } \\
\text { AC nos domínios do SPPC } \\
\text { entre as avaliaçóes das crianças } \\
\text { e de seus pais. }\end{array}$ \\
\hline $\begin{array}{l}\text { Ziebell et } \\
\text { al. (2009), } \\
\text { Austrália. }\end{array}$ & $\begin{array}{l}\text { Avaliar a relação entre o } \\
\text { desempenho físico, a per- } \\
\text { cepçấo de competência e o } \\
\text { AC global em crianças com } \\
\text { e sem diplegia espástica. }\end{array}$ & $\begin{array}{l}\text { Transversal. } \\
16 \text { crianças, sendo: } 8 \text { com diplegia } \\
\text { espástica, níveis I, II ou III do } \\
\text { GMFCS, } 3 \text { meninos e } 5 \text { meninas, } \\
\text { com idade entre } 7 \text { e } 11 \text { anos, e } \\
8 \text { com desenvolvimento típico, } \\
\text { de mesma idade e sexo que seus } \\
\text { pares. }\end{array}$ & $\begin{array}{l}\text { Autoconceito. } \\
\text { Versão modificada } \\
\text { por Ziebell (2006) } \\
\text { do SPPC de Harter } \\
(1985) \text {. }\end{array}$ & $\begin{array}{l}\text { Crianças com diplegia espástica } \\
\text { podem apresentar AC global } \\
\text { menos positivo do que as } \\
\text { crianças com DT, uma vez que } \\
\text { os escores foram menores em } \\
\text { crianças com PC diplégica em } \\
\text { dois domínios: na competência } \\
\text { motora fina e no autoconceito } \\
\text { global. }\end{array}$ \\
\hline $\begin{array}{l}\text { Russo et al. } \\
\text { (2008), } \\
\text { Austrália. }\end{array}$ & $\begin{array}{l}\text { Comparar a autoestima, } \\
\text { o AC e a QV em crianças } \\
\text { com PC hemiplégica e seus } \\
\text { pares com DT. }\end{array}$ & $\begin{array}{l}\text { Transversal. } \\
172 \text { crianças, sendo: } 86 \text { crianças } \\
\text { com PC hemiplégica, níveis I, II } \\
\text { ou III do GMFCS, } 54 \text { meninos e } \\
32 \text { meninas, na faixa etária de } 3 \text { a } \\
16 \text { anos e } 86 \text { com DT, de mesma } \\
\text { idade e sexo que seus pares. }\end{array}$ & $\begin{array}{l}\text { Autoconceito. } \\
\text { SPPC de Harter } \\
\text { (1985); Pictorial } \\
\text { Scale of Perceived } \\
\text { Competence and } \\
\text { Social Acceptance } \\
\text { de Harter e Pike } \\
\text { (1984). }\end{array}$ & $\begin{array}{l}\text { Diferenças na média dos } \\
\text { escores do AC entre os grupos, } \\
\text { favorecendo o grupo de } \\
\text { crianças com DT e indicando } \\
\text { menor AC nas dimensôes de } \\
\text { competência física, compe- } \\
\text { tência atlética e competência } \\
\text { acadêmica para as crianças com } \\
\text { PC hemiplégica. }\end{array}$ \\
\hline $\begin{array}{l}\text { Shields et } \\
\text { al. (2007), } \\
\text { Austrália. }\end{array}$ & $\begin{array}{l}\text { Investigar se o AC de } \\
\text { crianças com PC difere do } \\
\text { de crianças com DT. }\end{array}$ & $\begin{array}{l}\text { Transversal. } \\
94 \text { crianças, sendo: } 47 \text { com PC } \\
\text { do tipo diplegia ou hemiplegia } \\
\text { espástica e níveis I, II ou III } \\
\text { do GMFCS, distribuídos em } \\
24 \text { meninos e } 23 \text { meninas com } \\
\text { idade entre } 8 \text { e } 16 \text { anos, e } 47 \text { sem } \\
\text { deficiência, de mesma idade e sexo } \\
\text { que seus pares. }\end{array}$ & $\begin{array}{l}\text { Autoconceito. } \\
\text { Self-Perception } \\
\text { Profile for Children } \\
\text { de Harter (1985). }\end{array}$ & $\begin{array}{l}\text { Năo houve diferenças entre os } \\
\text { grupos nos domínios de AC glo- } \\
\text { bal, aparência física ou conduta } \\
\text { comportamental. Os escores } \\
\text { de AC foram menores para as } \\
\text { crianças com PC nos domínios } \\
\text { de competência acadêmica, } \\
\text { aceitaçấo social e competência } \\
\text { atlética quando comparados aos } \\
\text { das crianças com DT. }\end{array}$ \\
\hline
\end{tabular}




\begin{tabular}{|c|c|c|c|c|}
\hline $\begin{array}{l}\text { Autoria, } \\
\text { ano e local }\end{array}$ & Objetivo do estudo & Desenho do estudo e amostra & $\begin{array}{l}\text { Variável investigada } \\
\text { e instrumento de } \\
\text { medida }\end{array}$ & $\begin{array}{l}\text { Desfecho em relaçáo ao } \mathrm{AC} \\
\text { ou } \mathrm{AE}\end{array}$ \\
\hline $\begin{array}{l}\text { Shuengel et } \\
\text { al. (2006), } \\
\text { Holanda. }\end{array}$ & $\begin{array}{l}\text { Examinar a relevância da } \\
\text { DF para o AC global e em } \\
\text { seus domínios em crianças } \\
\text { com PC. }\end{array}$ & $\begin{array}{l}\text { Longitudinal. } \\
80 \text { crianças com PC, sendo } 49 \\
\text { meninos e } 31 \text { meninas, com idade } \\
\text { entre } 8 \text { e } 12 \text { anos e diferentes tipos } \\
\text { de PC. }\end{array}$ & $\begin{array}{l}\text { Autoconceito. } \\
\text { Escalas derivadas } \\
\text { da versăo holandesa } \\
\text { de Vermeer (2000) } \\
\text { do SPPC de Harter } \\
\text { (1985) para uso com } \\
\text { crianças com PC. }\end{array}$ & $\begin{array}{l}\text { O AC das crianças com PC } \\
\text { foi comparável ao da amostra } \\
\text { normativa holandesa, exceto } \\
\text { para o domínio de competên- } \\
\text { cia atlética. }\end{array}$ \\
\hline $\begin{array}{l}\text { Missiuna et } \\
\text { al. (2006), } \\
\text { Canadá. }\end{array}$ & $\begin{array}{l}\text { Determinar se crianças com } \\
\text { deficiência, entre } 6 \text { e } 9 \text { anos } \\
\text { de idade, podem avaliar sua } \\
\text { AE em determinadas tarefas } \\
\text { cotidianas. }\end{array}$ & $\begin{array}{l}\text { Longitudinal. } \\
117 \text { crianças, sendo: } 80 \text { meninos } \\
\text { e } 37 \text { meninas), entre } 6 \text { e } 9 \text { anos de } \\
\text { idade com diferentes problemas } \\
\text { no neurodesenvolvimento. }\end{array}$ & $\begin{array}{l}\text { Autoeficácia. } \\
\text { PEGS de Missiuna, } \\
\text { Pollock e Law } \\
(2004) \text {. }\end{array}$ & $\begin{array}{l}\text { Crianças com deficiência } \\
\text { entre } 6 \text { e } 9 \text { anos săo capazes de } \\
\text { informar sua AE. Pais e pro- } \\
\text { fessores avaliaram as crianças } \\
\text { como menos competentes em } \\
\text { comparação às avaliaçóes que } \\
\text { as crianças com deficiência } \\
\text { fizeram de si. Crianças com DI } \\
\text { se classificaram como menos } \\
\text { competentes que as outras } \\
\text { crianças da amostra. }\end{array}$ \\
\hline
\end{tabular}

Quadro 1- Caracterização dos artigos incluídos na revisão sistemática.

Fonte: elaboração própria.

Legenda: $\mathrm{AC}=$ autoconceito. $\mathrm{AE}=$ autoeficácia. $\mathrm{DF}=$ deficiência física. $\mathrm{DT}=$ desenvolvimento típico. $\mathrm{QV}=$ qualidade de vida.

PC $=$ paralisia cerebral. SPPC $=$ Self-Perception Profile for Children.

Destaca-se que todos os estudos selecionados na amostra final são estrangeiros, apenas um deles aborda o senso de autoeficácia (MISSIUNA et al., 2006) e seis são pesquisas que investigaram sobre o autoconceito em crianças com deficiência física, especificamente na população de crianças com paralisia cerebral (SOYUPEK et al., 2010; DUNN et al., 2009; ZIEBELL et al., 2009; RUSSO et al., 2008; SHIELDS et al., 2007; SCHUENGEL et al., 2006).

Em relação ao autoconceito em crianças com paralisia cerebral (PC), Soyupek et al. (2010) realizaram pesquisa na cidade de Isparta, Turquia, com o objetivo de identificar se a qualidade de vida e o autoconceito em crianças com PC diferem dos de crianças sem deficiência; e investigar variáveis preditivas que podem afetar a qualidade de vida e o autoconceito destas crianças. Participaram 40 crianças com PC, de todos os níveis de gravidade motora, conforme o Gross Motor Function Classification System (GMFCS) (PALISANO et al., 1997), com idade entre nove e 18 anos e 46 pares sem deficiência, de mesma idade e sexo.

No referido estudo, o autoconceito foi mensurado por meio do Piers-Harris Selfconcept Scale (PIERS, 1969) e os resultados revelaram diferenças nas médias dos escores, favorecendo o grupo controle, ou seja, as crianças com PC apresentaram autoconceito mais negativo em comparação com as crianças sem PC. Os pesquisadores também investigaram o efeito do gênero e da idade sobre os escores do autoconceito e observaram uma tendência das crianças de menor idade do grupo com PC terem menores escores de autoconceito do que as crianças do grupo sem deficiência (SOYUPEK et al., 2010).

$\mathrm{Na}$ investigação do autoconceito em função de outras variáveis, foram encontradas correlaçóes entre os escores do autoconceito e o tipo de escola da criança - menores escores 
do autoconceito foram encontrados para crianças que frequentavam escola especial quando comparadas às que estudavam em escola regular. Contudo, não foram encontradas correlações entre os escores de autoconceito e a idade e o sexo das crianças, o tipo de PC e o nível GMFCS de gravidade motora (SOYUPEK et al., 2010).

Em relação a correlação do autoconceito com o tipo de escola, os autores discutem a oferta de oportunidades para a interação com colegas e outras interaçóes nas escolas e ressaltam a necessidade de mais pesquisas para investigar por que as autoavaliaçóes das crianças são afetadas pelo tipo de escola que frequentam (SOYUPEK et al., 2010).

Nesta direção, supóe-se que provavelmente, este resultado possa estar relacionado à baixa oportunidade de experiências desafiadoras que são ofertadas a estas crianças na escola especial. Ao frequentarem escolas regulares, é possível que as crianças vivenciem interaçóes sociais diversas com seus pares e que o julgamento sobre o autoconceito se amplie quando dimensóes relativas à esta vivência são oportunizadas. Atividades de ensino, de lazer, esportivas, culturais e sociais devem ser ofertadas neste tipo de escola, valorizando a equiparação das oportunidades e sustentação das diferenças individuais, para que todos aprendam a conviver na diversidade. Compreende-se que a convivência com a diversidade permite a todos testemunharem sobre seus próprios potenciais e limites, além de possibilitar ver no outro estes mesmos atributos.

A partir da compreensão de que o autoconceito é importante para os familiares e profissionais que lidam com crianças com PC, porque ao saber o que as crianças pensam sobre suas competências, estas podem ser consideradas na determinação das metas de intervenção, Dunn et al. (2009) investigaram se havia diferenças entre o autoconceito de crianças com PC e a percepção de seus pais em relação as habilidades das crianças, além de avaliar a força de associação entre as avaliaçóes das crianças e de seus pais.

Participaram do estudo 30 crianças (14 meninas e 16 meninos), entre oito e 16 anos de idade, com hemiplegia ou diplegia espástica, níveis I ou II do GMFCS e seus pais. As crianças responderam o Self-Perception Profile for Children (SPPC) (HARTER, 1985), que avalia seis domínios do autoconceito: autoconceito global, competência acadêmica, aceitação social, competência atlética, aparência física e conduta comportamental, enquanto os pais responderam ao Parent Rating Scale que acompanha o SPPC e avalia os mesmos domínios, com exceção do autoconceito global (DUNN et al., 2009).

Os resultados apontaram diferenças entre pais e crianças nos domínios de competência atlética e aparência física. A média do autoconceito no domínio de aparência física avaliada pelos pais foi maior e a de competência atlética menor, quando comparadas às médias de avaliação das crianças sobre si mesmas. Náo houve nenhuma associaçáo entre os escores do autoconceito nos domínios do SPPC entre as avaliaçóes das crianças e de seus pais, indicando que os pais participantes da investigação não foram capazes de avaliar com precisão o autoconceito dos filhos com PC (DUNN et al., 2009).

Ziebell et al. (2009) realizaram estudo em Melbourne, na Austrália, com objetivo de avaliar a relação entre o desempenho físico, a percepção de competência e o autoconceito global em crianças com e sem diplegia espástica. Participaram oito crianças com diplegia espástica e oito crianças com desenvolvimento típico, com idade entre sete e 11 anos. Todas as crianças 
foram examinadas em relação às habilidades motoras grossa e fina e responderam à versão modificada do SPPC. As habilidades motoras grossas foram examinadas por fisioterapeutas com uso de protocolos e as habilidades motoras finas de membros superiores foram examinadas por terapeutas ocupacionais com uso de testes específicos.

Como resultado, Ziebell et al. (2009) observaram que além de ter a capacidade física reduzida, as crianças com diplegia espástica podem apresentar autoconceito global menos positivo do que as crianças com desenvolvimento típico, uma vez que os escores foram menores em crianças com PC diplégica em dois domínios: na competência motora fina e no autoconceito global.

Correlaçôes positivas entre avaliações de desempenho físico e alguns domínios do SPPC estavam presentes, embora a força e a direção das relaçóes tenham sido diferentes para cada grupo em alguns casos (ZIEBELL et al., 2009). Resultado este que pode estar relacionado ao limite amostral utilizado na pesquisa, que envolveu um número pequeno de participantes para o alcance de correlaçóes significativas entre as variáveis investigadas.

Em investigação na Austrália sobre a autoestima, o autoconceito e a qualidade de vida de crianças com PC hemiplégica em comparação com seus pares de desenvolvimento típico, Russo et al. (2008) avaliaram 86 crianças com PC hemiplégica, 54 meninos e 32 meninas, na faixa etária de três a 16 anos e seus pares, com desenvolvimento típico, de mesma idade e sexo. A autoestima e o autoconceito foram avaliados com o SPPC (para 55 pares de crianças com idade entre oito e 16 anos) e com o Pictorial Scale of Perceived Competence and Social Acceptance (para 31 pares de crianças com idades entre três e sete anos) (RUSSO et al., 2008).

Os resultados do estudo australiano indicaram diferenças na média dos escores do autoconceito entre os grupos, favorecendo o grupo de crianças típicas e indicando menor autoconceito nas dimensôes de competência física, competência atlética e competência acadêmica para as crianças com PC hemiplégica. Entretanto, na escala de aceitação materna os resultados favoreceram as crianças com PC (RUSSO et al., 2008).

Com o propósito de investigar se o autoconceito de crianças com PC difere do de crianças sem deficiência, Shields et al. (2007) realizaram pesquisa também em Melbourne, Austrália, com 47 crianças com diplegia ou hemiplegia espástica e níveis I, II ou III do GMFCS, 24 meninos e 23 meninas, com idade entre oito e 16 anos e seus pares sem deficiência. Todos os domínios do SPPC foram utilizados e os resultados indicaram não haver diferenças entre os grupos nos domínios de autoconceito global, aparência física ou conduta comportamental. Os escores de autoconceito foram menores para as crianças com PC nos domínios de competência acadêmica, aceitação social e competência atlética, quando comparados aos das crianças com desenvolvimento típico (SHIELDS et al., 2007).

Em estudo longitudinal realizado ao longo de três anos na Holanda, por Schuengel et al. (2006), foram recrutadas 80 crianças com PC, meninos e meninas, com idade entre oito e 12 anos com o objetivo de examinar a relevância da deficiência física para o autoconceito global e em seus domínios em crianças com PC. O autoconceito global e seus domínios foram avaliados com versóes derivadas da versão holandesa do SPPC, desenvolvido por Vermeer (2000) para uso com crianças com PC, como por exemplo, a escala pictórica direcionada a crianças de menor idade ou com dificuldades para compreender o instrumento original. O Gross Motor 
Function Measure (GMFM) também foi aplicado para avaliar a função motora das crianças com PC (SCHUENGEL et al., 2006).

Como resultado, o autoconceito das crianças com PC participantes do estudo foram comparáveis aos da amostra normativa holandesa, exceto para o domínio de competência atlética. Dentro da amostra com PC, o GMFM mostrou efeito específico sobre o domínio de competência motora (SCHUENGEL et al., 2006). Os autores concluíram que as crianças com PC parecem ser resistentes aos desafios colocados para o seu autoconceito, causados por suas deficiências e que a relevância da deficiência física parece ser específica ao domínio de competência motora. Para Schuengel et al. (2006), de maneira equivalente às crianças sem deficiência, as crianças com PC mantêm, em geral, um autoconceito positivo.

Ao apresentarem, em geral, um autoconceito positivo e semelhante ao de crianças típicas, este achado nos parece positivo e pode reforçar que crianças com deficiência física percebem a sua competência como adequada para atender as demandas e expectativas para o seu estágio de desenvolvimento, com relevância expressa apenas em algum dos domínios do autoconceito. Isto pôde ser observado tanto por Schuengel et al. (2006), quanto por Oliveira (2016), em estudo transversal realizado em Natal, na região nordeste do Brasil, que também usou o SPPC para avaliar o autoconceito de 20 crianças com deficiência física e de 36 crianças com desenvolvimento típico entre oito e 12 anos de idade. Sendo que no estudo de Schuengel et al. (2006) a exceção foi para o domínio de competência atlética, enquanto no de Oliveira (2016) foi para o domínio de aparência física, diferença esta que talvez possa ser explicada por aspectos culturais, como o que é valorizado pela criança em cada cultura.

Acerca do senso de autoeficácia, Missiuna et al. (2006) realizaram estudo em Ontario, no Canadá, com 117 crianças com diferentes problemas no neurodesenvolvimento (paralisia cerebral, espinha bífida, transtorno do desenvolvimento da coordenação, transtorno do déficit de atenção e hiperatividade, transtornos de aprendizagem, atraso no desenvolvimento, entre outras síndromes), recrutadas durante o período compreendido entre os anos de 2000 e 2002 em serviços de Terapia Ocupacional, juntamente com seus pais e professores. O instrumento Perceived Efficacy and Goal Setting System (PEGS) (MISSIUNA et al., 2006) foi utilizado com o objetivo de determinar se as crianças com deficiência, na faixa etária de seis a nove anos de idade, poderiam avaliar a sua competência na realização das atividades cotidianas, ou seja, sua autoeficácia em determinadas tarefas. Pais e professores também completaram um questionário que acompanha o PEGS para avaliar as competências das crianças.

Os resultados revelaram que as crianças com deficiência na faixa etária investigada são capazes de informar sobre sua autoeficácia. Pais e professores avaliaram as crianças como menos competentes em comparação às avaliaçóes que as crianças com deficiência fizeram de si (MISSIUNA et al., 2006). Ainda, neste estudo, não encontraram diferença na autoeficácia das crianças em função da sua escolaridade, sexo ou idade, mas foram identificadas diferenças entre os tipos de deficiência. Crianças com transtorno do déficit de atenção e hiperatividade e transtornos psiquiátricos se classificaram como consideravelmente mais competentes do que as crianças com outras deficiências, com destaque para o resultado de que as crianças com deficiências físicas se classificaram como muito menos competentes que as outras crianças da amostra (MISSIUNA et al., 2006). 
Pôde-se observar que todos os estudos incluídos nesta revisão investigaram o autoconceito em crianças com PC, e para tanto, aplicaram instrumentos que consideram o autoconceito como constructo multidimensional, entre eles, destaca-se o SPPC de Harter (1985) e versóes modificadas do mesmo.

Além das diferenças na instrumentação utilizada nos estudos, a amostra de participantes também foi distinta em termos de faixa etária das crianças, classificação topográfica e tipo de desordem motora da PC, ainda que o nível de comprometimento motor das crianças seja semelhante na maioria dos estudos (níveis I, II ou III do GMFCS). Desta maneira, hipotetiza-se que aspectos como idade e gravidade dos comprometimentos na criança possam ser variáveis mediadoras do impacto da condição de ter uma deficiência física no autoconceito infantil.

No geral, observa-se que não há uma conformidade na literatura sobre o autoconceito nesta população. Por um lado, a literatura internacional tem apontado que estas crianças apresentam baixo autoconceito em diferentes domínios, quando comparadas às crianças com desenvolvimento típico (SOYUPEK et al., 2010; ZIEBELL et al. 2009; RUSSO et al., 2008). Por outro lado, Schuengel et al. (2006) indicam que estas crianças apresentam um autoconceito positivo, de maneira equivalente às crianças sem deficiência (comparação com dados da amostra normativa holandesa), com exceção do domínio de competência atlética. Ao mesmo tempo em que Shields et al. (2007) sugerem que apesar de as crianças com PC poderem se sentir menos competentes em certos aspectos do seu autoconceito, elas podem não apresentar um autoconceito global mais baixo do que as crianças típicas.

Embora alguns estudos tenham apontado diferenças no autoconceito entre crianças com PC e típicas, tais diferenças foram observadas para distintos domínios do autoconceito (como para competência física, competência atlética e competência acadêmica no estudo de Russo et al., 2008; competência motora fina e autoconceito global em Ziebell et al., 2009), o que dificulta tecer consideraçóes. Sendo que estas divergências podem estar relacionadas ao método de investigação que foi proposto por cada pesquisa, com a utilização de variados instrumentos de medida e envolvendo amostra consideravelmente distinta de crianças (tamanho da amostra, faixa etária, tipo de PC e nível de gravidade motora).

Em contrapartida aos estudos que indicam mais baixo autoconceito em crianças com deficiência física, o fato de alguns estudos (SHIELDS et al., 2007; SCHUENGEL et al., 2006) não apontarem diferenças significativas nas dimensóes do autoconceito, com exceção da competência atlética por Schuengel et al. (2006), entre os grupos de crianças com e sem deficiência física nos parece bastante positivo, enfraquecendo a visão social/estigma que existe, principalmente entre os adultos, familiares e profissionais, de que a condição de deficiência física faz com que estas crianças possam não se sentir bem consigo mesmas (SHIELDS et al., 2006).

Assim, ainda não há evidências suficientes para concluir que este constructo seja inferior em crianças com PC, de maneira equivalente aos achados de Shields e colaboradores, que realizaram revisão sistemática sobre o assunto no ano de 2006, com o propósito de verificar se a suposição de que crianças e jovens com PC frequentemente têm assumido autoconceito mais baixo é sustentada por pesquisas empíricas. Estes autores identificaram artigos por busca nas bases de dados CINAHL, Biblioteca Cochrane, EMBASE, ERIC, MEDLINE, PsychINFO e PubMed. De 1.355 artigos inicialmente identificados, apenas seis atenderam aos critérios de 
inclusão: os participantes terem diagnóstico de PC com idade abaixo de 18 anos; a pesquisa ter comparado o autoconceito de crianças com PC com o de crianças sem deficiência ou com dados normativos; estudo completo em inglês; estudo ter registrado as variáveis mensuradas. A qualidade dos estudos identificados também foi considerada (SHIELDS et al., 2006).

Os resultados da revisão de Shields et al. (2006) sugerem que algumas crianças com PC podem apresentar autoconceito mais baixo em alguns domínios quando comparadas a crianças sem deficiência, entretanto, sem evidências para concluir que crianças com PC têm, em geral, autoconceito mais baixo do que crianças sem deficiência, o que reforça a necessidade de futuras investigaçóes, inclusive em cenário brasileiro.

Destaca-se que diferenças culturais possam mediar a autoavaliação infantil, uma vez que Taylor et al. (2014) apontam aspectos culturais como um dos fatores que influenciam o autoconceito e ressalta que à medida que a criança internaliza valores dos pais e dos pares, a cultura começa a influenciar no seu autoconceito. Desta forma, é possível que pesquisas com crianças brasileiras possam evidenciar resultados divergentes dos indicados pela literatura internacional acerca das autoavaliações infantis, tanto em crianças com deficiência física, como em crianças típicas.

No que se refere ao autoconceito de crianças com PC, o estudo de Dunn et al. (2009) ainda sugere que há diferenças significativas na avaliação do autoconceito pelas crianças com PC e por seus pais, o que reforça uma implicação prática de os pesquisadores ou profissionais colherem estas informaçóes a partir das próprias crianças. Isto também se aplica a autoeficácia, como pôde ser observado no estudo de Missiuna et al. (2006), onde pais e professores avaliaram as crianças como menos competentes em comparação às avaliaçóes que as próprias crianças com deficiência (incluindo as com PC) fizeram de si.

Como indicado anteriormente, apenas um estudo, o de Missiuna et al. (2006), foi incluído nesta revisão da literatura por abordar a autoeficácia. Este apontou que crianças com deficiência física se classificaram muito menos competentes que as demais crianças da amostra que tinham outros problemas no neurodesenvolvimento, por meio do PEGS (MISSIUNA; POLLOCK; LAW, 2004).

Ressalta-se que as diferenças encontradas por Missiuna et al. (2006) foram entre os diferentes tipos de deficiências e não em função de ter ou não uma condição de deficiência. Dessa maneira, julga-se que futuras investigaçóes complementares, com foco na autoeficácia de crianças com deficiência física e de crianças com desenvolvimento típico, poderiam confirmar ou refutar os achados do presente estudo e melhor compreender o constructo nesta população.

\section{Conclusấo}

Ao buscar identificar estudos que investigaram sobre o autoconceito e a autoeficácia em crianças com deficiência física, foi possível identificar o estado da arte de pesquisas neste domínio e lacunas de conhecimento na produção científica existente sobre o assunto.

Pode-se notar que, em geral, os resultados indicam que não há conformidade sobre o autoconceito de crianças com paralisia cerebral, não existindo evidências suficientes para concluir que este constructo seja inferior nestas crianças. Em relação a autoeficácia, em que apenas 
um estudo foi localizado, crianças com deficiência física se classificam como menos competentes que crianças com outros problemas no neurodesenvolvimento.

Tais resultados precisam ser considerados à luz das divergências metodológicas encontradas nos estudos incluídos na investigação, como características das amostras de crianças participantes e os instrumentos de medida utilizados.

Quanto às publicaçôes, observou-se a predominância de pesquisas estrangeiras e uma carência de trabalhos nacionais na área que se debrucem sobre o autoconceito e a autoeficácia de crianças com deficiência física na realidade brasileira. Sendo que aspectos culturais muito provavelmente devem repercutir sobre as autoavaliaçóes infantis.

Espera-se que esta revisão possa contribuir para a ampliação do conhecimento de profissionais da Educação e Saúde acerca das autoavaliaçóes nesta população, a partir da compreensão de que o autoconceito e a autoeficácia têm importante papel nos processos de motivação, de aprendizagem e comportamentais, que por sua vez, agem como mediadores do desenvolvimento humano. Nesse sentido, estes constructos são relevantes para os que lidam com crianças com deficiência física, porque ao saber como as crianças pensam sobre si mesmas e sobre suas competências, estas podem ser consideradas na determinação das metas de intervenção em contextos diversos, incluindo o escolar.

\section{REFERÊNCIAS}

ARAÚJO, M.C.C. O autoconceito nos contextos familiar, social e escolar. 2012. 111f. Dissertação (Mestrado em Educação) - Faculdade de Educação, Universidade Estadual de Campinas, Campinas, 2012.

BANDURA, A. Social foundation of thought and action: a cognitive theory. Englewood Cliffs: PrenticeHall, 1986.

BANDURA, A. Regulation of cognitive processes through perceived self-efficacy. Developmental Psychology, v.25, p.729-735, 1989.

BANDURA, A. et al. Multifaceted impact of self-efficacy beliefs on academic functioning. Child Development, v.67, p.1206-1222, 1996.

BANDURA, A. Self-efficacy: the exercise of control. New York: W. H. Freeman, 1997.

BANDURA, A.; AZZI, R.G.; POLYDORO, S. Teoria social cognitiva: conceitos básicos. Porto Alegre: Artmed, 2008.

BAUM, C.M.; CHRISTIANSEN, C. Person-environment-occupation-performance: an occupationbased framework for practice. In: CHRISTIANSEN, C.; BAUM, C.M. Occupational therapy: performance, participation and well-being. Thorofare: Professional Book Division, 2005.

BAYDALA, A.; HIEBERT, B.; MALEC, C. Lifestyle interventions: reasons for therapeutic outcome. Canadian Journal of Counselling, v.34, p.75-84, 2000.

BRASIL. Diretrizes metodológicas: elaboração de revisão sistemática e metanálise de ensaios clínicos randomizados. Ministério da Saúde, Secretaria de Ciência, Tecnologia e Insumos Estratégicos, Departamento de Ciência e Tecnologia. Brasília, DF: Ministério da Saúde, 2014. 
CANDIEUX, A. Psychometric properties of a pictorial self-concept scale among young learning disabled pupils. Psychology in the schools, v.33, n.3, p.221-229, 1996.

COOPERSMITH, S. The antecedents of self-esteem. San Francisco: W. H. Freeman, 1967

CORREDEIRA, R. et al. Como avaliar a percepção de competência e aceitação social de crianças com paralisia cerebral? Estudo inicial para a determinação das propriedades psicométricas da versão portuguesa da dutch pictorial scale of perceived competence and social acceptance in children with cerebral palsy. Revista Brasileira de Educação Especial, v.13, n.3, p.325-344, 2007.

DUNN, J.C.; DUNN, J.G.H. Psychosocial determinants of physical education behavior in children with movement difficulties. Adapted Physical Activity Quarterly, v.23, p.293-309, 2006.

DUNN, N. et al. Comparing the self-concept of children with cerebral palsy to the perceptions of their parents. Disability and Rehabilitation, v.31, n.5, p.387-393, 2009.

FARIA, L.; FONTAINE, A. Adaptação do self-perception profile for children (SPPC) de Harter a crianças e pré-adolescentes. Psicologia, v.10, n.3, p.129-142, 1995.

FERNANDES, A.M.; MILANI, R.G. A depressão infantil, o rendimento escolar e a autoeficácia: uma revisão da literatura. Revista Cesumar - Ciências Humanas e Sociais Aplicadas, v.15, n.2, p.381-403, 2010.

FIERRO, A. Personalidade e aprendizagem no contexto escolar. In: COLL, C.; PALÁCIOS, J.; MARCHESI, A. Desenvolvimento psicológico e educação II: psicologia da educação. Porto Alegre: Artes Médicas, 1996.

HARTER, S. Manual self-perception profile for children. Denver: University of Denver, 1985.

HARTER, S. Historical roots of contemporary issues involving self-concept. In: BRACKEN, B. Handbook of self-concept: developmental, social and clinical considerations. New York: Wiley, 1996.

LENT, R.W.; MADDUX, J.E. Self-efficacy: building a sociocognitive bridge between social and counseling psychology. The Counseling Psychologist, v.25, p.240-255, 1997.

MEDEIROS, P.C. et al. A auto-eficácia e os aspectos comportamentais de crianças com dificuldade de aprendizagem. Psicologia: Reflexão e Crítica, v.13, n.3, p.327-336, 2000.

MISSIUNA, C.; POLLOCK, N.; LAW, M. Perceived efficacy and goal setting system (PEGS). San Antonio: Psychological Corporation, 2004.

MISSIUNA, C.; POLLOCK, N.; LAW, M. et al. Examination of the perceived efficacy and goal setting system (PEGS) with children with disabilities, their parents, and teachers. American Journal of Occupational Therapy, v.60, p.204-214, 2006.

NEVES, S.P.; FARIA, L. Auto-conceito e auto-eficácia: semelhanças, diferenças, inter-relação e influência no rendimento escolar. Revista da Faculdade de Ciências Humanas e Sociais, v.6, p.206-218, 2009.

OLIVEIRA, A.K.C. Autoconceito, autoeficácia e parentalidade: crianças com deficiência física, com desenvolvimento típico e seus familiares. 2016. 152f. Tese (Doutorado em Educação Especial) - Programa de Pós-Graduação em Educação Especial, Universidade Federal de São Carlos, São Carlos, 2016.

PAJARES, F; VALIANTE, G. The predictive and mediational role of the writing self-efficacy beliefs of upper elementary students. Journal of Educational Research, v.90, p.353-360, 1997. 
PALISANO, R. et al. Developmental and reliability of a system to classify gross motor function in children with cerebral palsy. Developmental Medicine and Child Neurology, v.39, n.4, p.214-223, 1997.

PIERS, E. Manual for the piers-harris children's self-concept scale. Nashville: Counsellor Recordings and Tests, 1969.

RUSSO, R.N. et al. Self-esteem, self-concept, and quality of life in children with hemiplegic cerebral palsy. Journal of Pediatrics, v.153, n.4, p.473-477, 2008.

SCHUENGEL, C. et al. Self-worth, perceived competence, and behaviour problems in children with cerebral palsy. Disability and Rehabilitation, v.28, n.20, p.1251-1258, 2006.

SCHUNK, D.H. Self-efficacy, motivation, and performance. Journal of Applied Sport Psychology, v.7, n.2, p.112-137, 1995 .

SHIELDS, N. et al. A systematic review of the self-concept of children with cerebral palsy compared with children without disability. Developmental Medicine and Child Neurology, v.48, n.2, p.151-157, 2006.

SHIELDS, N. et al. Self-concept of children with cerebral palsy compared with that of children without impairment. Developmental Medicine and Child Neurology, v.49, n.5, p.350-354, 2007.

SOYUPEK, F. et al. Do the self-concept and quality of life decrease in CP patients? Focussing on the predictors of self-concept and quality of life. Disability and Rehabilitation, v.32, n.13, p.1109-1115, 2010.

SUEHIRO, A.C.B. et al. Avaliação do autoconceito no contexto escolar: análise das publicaçóes em periódicos brasileiros. Psicologia, Ciência e Profissão, v.29, n.1, p.18-29, 2009.

TAYLOR, C.R. et al. Fundamentos da enfermagem: a arte e a ciência do cuidado de enfermagem. 7.ed. São Paulo: Artmed, 2014.

VERMEER A. De competentie belevings schaal voor kinderen met cerebrale parese: Handleiding. The Self-Perception Profile for children with cerebral palsy: Manual. Utrecht, The Netherlands: Universiteit Utrecht, 2000.

ZIEBELL, M. et al. The relationship between physical performance and self-perception in children with and without cerebral palsy. Australian Occupational Therapy Journal, v.56, p.24-32, 2009. 
OLIVEIRA, A.K.C; MATSUKURA, T.S.; FONTAINE, A.M.G.V. 